\title{
3 The age profile of European welfare states
}

\section{A source of intergenerational conflict?}

\author{
Ann-Helén Bay and Axel West Pedersen
}

\section{Introduction}

It has often been claimed that population aging will lead to intensified distributional conflicts in the welfare state between the young and the old. Traditionally, benefits towards the elderly have enjoyed strong public support in most welfare states. However, with population aging, the costs related to the provision of oldage pensions and old-age care are increasing, and this could lead to increased intergenerational conflict. ${ }^{1}$ Younger population segments are expected to oppose the heavy burden that pension systems and public provision of elderly care place upon them, while the elderly could use their strength in numbers to push through political priorities favoring themselves.

In a groundbreaking study of the development of the standard of living among elderly and children in the American society, Samuel H. Preston came to the widely cited conclusion that "conditions have deteriorated for children and improved dramatically for the elderly and demographic change has been intimately involved in these developments" (Preston, 1984, p. 436).

The aging of the population has according to Preston had a major influence on political priorities in the American welfare state in favor of the elderly, and he points to three sources of self-interested support for policies benefiting the elderly in particular: "the elderly themselves, the working-age population who wants to avoid elderly's need for family support and the same working-age population who cares for their own well-being as elderly" (Preston 1984, p. 446). Since Preston's seminal article, several studies have been undertaken to investigate the age profile of democratic welfare states and the drivers behind age policies as well as individual attitudes (see e.g. Vanhuysse \& Goerres, 2012; Torp, 2015). A substantial amount of the research contributions deals with what for Preston is an important premise; that policy changes in favor of the elderly are the result of an aging electorate fighting for their own self-interests.

Julia Lynch (2006) joins Preston in his concerns about a potential bias in favor of the elderly in contemporary welfare policy. However, rather than seeing this as a universal trend driven by common changes in the age composition of the electorate, she proposes that the degree of elderly bias is contingent on the architecture of the existing welfare state and the nature of policymaking in different 
countries. She constructs an index-measuring per capita social expenditure on the elderly divided by per capita social expenditure to the nonelderly and finds dramatic variation in the degree of pro-elderly spending bias across OECD countries (Lynch 2006, p. 5 and p. 30). Her main conclusion is that "the age orientation of welfare is a largely unintended consequence of the structure of social programs and the mode of political competition in which politicians engage" (2006, p. 184).

Inspired by the comparative findings of Lynch and the contested premise of a self-serving, greying electorate, this chapter sets out to investigate the contemporary age orientation of welfare spending in selected European welfare states and voter preferences with respect to policies that benefit the elderly and families with children, respectively. Three main research questions will be pursued: (1) Does the pattern found by Lynch of large cross-national differences in the age profile of welfare state spending hold up, or have there been tendencies toward convergence over the last 15 years? (2) Does contemporary cross-national variation in the age orientation of welfare state spending align with cross-national variation in voter preferences? (3) To what extent do we see an age gradient in the voters' priorities over age-related welfare spending, and is this stronger in countries with a particularly elderly- biased profile of welfare spending?

The empirical analysis is based on a sample of 13 European countries. Before embarking on the empirical analysis, we offer a review of theoretical perspectives and previous research, followed by a presentation of our hypotheses and an introduction to our data and the methods applied.

\section{Voter preferences and age-related political priorities: theoretical perspectives and previous findings}

The premise of an aging electorate fighting politically for its own material interests is in accordance with standard models of political economy (Buchanan \& Tullock, 1969; Persson \& Tabellini, 2000): political parties competing for power are forced to adjust their programs to satisfy the preferences of the median voter who is assumed to be acting as an individual utility maximizer. Since important welfare programs like old-age pensions and child allowances benefit distinctive age groups, it is logical to expect a strong age cleavage in the degree of support for the respective programs among voters.

Studies of the relationship between age and individuals' welfare attitudes do however leave us with a somewhat mixed picture. Busemeyer et al. (2009) studied welfare attitudes in 14 OECD countries. They found considerable age-related preferences related to education, but modest effects of age on attitudes toward pensions. de Mello et al. (2016) studied attitudes toward government spending in 34 countries. They found that the elderly are less likely to support increased spending on education and more likely to support increased spending on pensions. They foresee increased tensions between generations in ageing societies (p. 1). Svallfors et al., on the other hand, conclude from a cross-country study of welfare opinions that age is not likely to emerge as an important social cleavage (2012, p. 182). 
Based on the assumption of the self-oriented median voter, Jensen (2012) makes a distinction between life cycle and labor market-oriented social programs. According to Jensen, the (middle class) median voter is less supportive of labor market programs as they mainly affect the risks of low-income individuals. The median voter favors social programs directed toward life cycle risks, as these are by and large uncorrelated with income. The distinction challenges the hypothesis of age-based conflicts about distribution; the median voter will push both sides of the political left-right dimension to prioritize life cycle-oriented programs at the expense of programs directed toward the poor.

While it is possible to construct an argument based on self-interest to explain why also the young should be sympathetic to spending on the elderly (because they expect to benefit in the future), it is more difficult to develop a similar account of support for family policies among the elderly. Goerres and Tepe (2010) have however suggested that the self-interest of the elderly can be modified by intergenerational solidarity within the family. They find empirical evidence supporting the hypothesis that the interaction with younger family members stimulates solidarity since the interaction is associated with more positive attitudes toward public spending on childcare among elderly voters.

The assumption of age-based interests as a premise for the individual's political preferences as well as the role of age policies played in the competition for power between political parties is challenged more fundamentally by alternative theories to the median voter theorem. According to the theory of symbolic politics, individuals form their political preferences based on a set of individually stable and culturally influenced political and social values, group stereotypes, sympathies, and antipathies (see Sears and Funk,1990 for a summary). Symbolic predispositions are "judgmental shortcuts, efficient ways to organize and simplify political choices" (Sniderman, Brody, \& Tetlock, 1991, p. 19). In the literature on the sources of individuals' attitudes toward social policies and the welfare state, particular attention has been paid to beliefs about the legitimacy of an individual's claim to benefits (Feldman \& Zaller, 1992, van Oorschot, 2006). Findings from research on welfare attitudes have revealed that individuals base their evaluation of welfare benefits on notions of deservingness and the potential for abuse (Roosma et al, 2014). Many have pointed out that the elderly are generally regarded as a most deserving group; aging is beyond the individual's control (Fernández, 2012) and benefits to the elderly can be seen as a reward for their efforts through life for the society and the family (Heclo, 1988).

The median voter theorem and the theory of symbolic politics attach important explanatory power to exogenous voter preferences. They both predict convergence in voters' attitudes and policies across countries. Either individual selfinterest or culturally imposed sympathy should encourage voters to prioritize benefits toward the elderly. In turn this must be expected to result in convergence in the actual policies pursued in different countries. These theories therefore have difficulties explaining cross-national variation in the age profile of social policies. In order to explain strong cross-national variation in the actual age profile of welfare policies, we either have to assume that some welfare states are not 
responsive to the political priorities of their voters or that the preferences of the voters are less predictable and homogenous than the theories would lead us to expect.

The idea that welfare policy is converging as a result of structural similarities in voter preferences is challenged by theories emphasizing the path dependency of social policies and the importance of established institutions for political interest formation and political reasoning. According to this perspective, different welfare states can be set on divergent development paths that tend to perpetuate or even reinforce themselves. A trivial explanation for political path dependency is the costs involved in changing institutions and encompassing policy measures. But most important is the role played by established institutions in the framing of the discourse: "defining the repertoire of more or less acceptable (and expectable) discursive interactions" (Schmidt, 2003, p. 319). According to Pierson, established policies constrain the decisions of policymakers as well as the preferences of voters $(1996,1998,2001)$. Voter preferences can play an important role also in this theory, but here they are assumed to be largely endogenous and conditioned by existing policies and institutional structures, and they can therefore be expected to diverge across countries rather than converge.

Lynch's study of the age profile of rich democracies puts a strong emphasis on the notion of path dependency. She suggests that an observed strong variation in the age profile of contemporary welfare states can be explained with reference to two analytical dimensions (Lynch, 2006, p. 55). The first refers to a distinction between countries with a historical legacy of universal, citizenship-based social programs and countries with a tradition for occupationally segmented social programs, both dating back to the birth of the welfare state in the early 20th century. In the first category she places the Nordic countries and the Anglo-Saxon countries (except the United States), while she places most Continental and Southern European countries in the second category. This dichotomy resonates with the more familiar distinction between "Biscmarckian" and "Beveridgean" welfare states (Palier, 2010), and it has affinities to Esping-Andersen's famous welfare state typology and in particular the distinction between Conservative/continental welfare states on the one hand and Social Democratic and Liberal welfare states on the other (Esping-Andersen, 1990).

According to Lynch, an intermediate group of countries can be identified that is characterized as having shifted path from an initial emphasis on occupationally segmented programs to more universal, citizen-based policies. In this intermediate group she places countries like Germany, France, the Netherlands, and Portugal. In order to explain why other countries with a similar historical legacy (particularly Southern European countries like Italy, Spain, and Greece, but also Austria, Belgium the United States and Japan) have remained stuck in the occupationally segmented path, she brings in the second dimension, which refers to the nature of political competition between parties: many of the countries where occupational programs persisted tend to be characterized by a political system where politicians offer tangible benefits to selective groups in return for votes ( $\mathrm{p}$. 63) ("clientelistic" political systems), in contrast to party competition in countries 
with universal programs that tends to be ideological and justified with reference to the benefits to society at large.

Lynch's empirical analysis seems to confirm that the age bias in welfare spending in favor of the elderly is particularly strong among countries that feature corporatist and occupationally segmented social policies and weakest among the group of countries with a legacy for citizenship-based social policies. The intermediate group of countries that are claimed to have changed paths after World War II toward more citizen-based policies are found to score somewhere in between the two other groups in terms of pro-elderly spending bias. She contends that these patterns are entrenched and therefore very difficult to change; the established age orientation seems "to create a kind of ideational feedback among elites, structuring how they perceive the welfare state to administer intergenerational justice, and thus setting new parameters for discussions about welfare retrenchment and reform" (p. 199).

\section{Outline of the empirical analysis and hypotheses}

We start out the empirical analysis by investigating whether Lynch's finding of a distinctive and stable pattern of widely different age profiles in welfare spending can still be identified. We then move on to elaborate on a topic suggested in Lynch's concluding remarks about topics for future research: the reaction to existing age policies among voters. Are voters in the respective countries also influenced by the path-dependent "ideational feedback among elites" so that they tend to support the different age policies pursued in the respective countries? In that case, we expect that cross-national variation in voter preferences aligns neatly with observed differences in the policies that are pursued in different countries. Or could it rather be the case that (median) voters in different countries tend to have exogenous and intrinsically similar preferences in line with standard political economy theory or motivated by universal ideas about justice between age groups so that we can identify a significant discrepancy between voter preferences and the policies pursued in countries with a strong pro-elderly spending bias? Finally, we are interested in finding out if a strong elderly-biased social policy will trigger a stronger age division in voter attitudes than a social policy with a more even distribution between spending on the young and the old. The strength of the debate about generational justice in the elderly-friendly American society gives reasons to expect stronger age division in voters' preferences in countries with mainly occupational-based social programs than in countries with citizen-based social programs. On the other hand, the political elite plays an important role in the development of social policies in the theory of path dependency. If voters are more or less detached from political decisions about social programs, there is no reason to expect that age has a stronger effect within some social policy regimes than in others, nor is there reason to expect a strong overlap between voters' priorities and the priorities pursued by governments in European welfare states. 


\section{Data and methods}

Our study covers 13 European countries. The criteria for selecting countries is (1) that they are covered in the study by Lynch and (2) that they are covered in the European Social Survey Round 8, in which a module on welfare attitudes allows us to investigate voter preferences toward policies that favor the elderly and policies that favor families with children.

The 13 countries are presented in Table 3.1. We have divided them into four groups according to a conventional typology of European welfare states (Leibfried, 1992; Ferrera, 1996): Social Democratic/Nordic, Liberal, Conservative/Continental, and Southern European welfare states. We prefer to use this typology over Lynch's less well-known threefold typology, but - as already discussed - the two typologies are fairly similar in their grouping of countries. The main difference is that the Social Democratic and Liberal welfare states are joined together by Lynch in a group characterized by citizen-based universal policies. The Southern European category corresponds largely with Lynch's category of corporatist and occupationally segmented welfare states, while the Conservative/Continental category corresponds roughly with Lynch's category of Mixed Systems.

In the first part of the empirical analysis, we use data on social expenditure from the so-called SOCX database provided by the OECD (OECD 2019), to study cross-national variation in the age profile of social expenditure and how it has changed in our 13 country cases between 2000 and 2015.

Although inspired by Lynch, we have chosen a somewhat different operationalization. Like Lynch, we look at total expenditure on pensions and social services to people aged $65+$ as an indicator of spending in favor of the elderly, but our indicator for spending on the "young" is different. While she uses total social expenditure on the nonelderly (including spending on unemployment, disability, and sickness benefits), we concentrate on social spending in favor of families with children (e.g. spending on cash benefits and services offered to families with children). We believe that this provides a more relevant contrast of social spending on the old versus the young. When taking a per capita perspective on spending in favor of the old and the young, we divide spending on the respective program areas by the number of people above the age of 65 (per capita spending on the

Table 3.1 Country cases, grouped according to welfare state type

\begin{tabular}{llll}
\hline $\begin{array}{l}\text { Social } \\
\text { democratic/-Nordic }\end{array}$ & Liberal & Conservative/-Continental & $\begin{array}{l}\text { Southern } \\
\text { European }\end{array}$ \\
\hline Sweden & United Kingdom & Germany & Italy \\
Norway & Ireland & France & Spain \\
Finland & The Netherlands & Austria & Portugal \\
& & Belgium & \\
\hline
\end{tabular}


elderly) and by the number of children below the age of 15 (per capita spending on children).

In the second and third parts of the analysis, we combine information on spending patterns with data on voter preferences about the government's responsibility for supporting the elderly and families with children.

Data on voter preferences are derived from the eighth round of the European Social Survey (ESS) that was implemented in 2016. This round of ESS was chosen because it is the latest wave containing a special module on welfare state attitudes. We have used two questions that tap attitudes toward supporting the elderly and families with children respectively: (1) "Should it be government's responsibility to ensure a reasonable standard of living for the old?" And (2) "How much responsibility do you think government should have to ensure sufficient childcare services for working parents?" Responses were registered on a scale of 0 to 10 . Ideally it would have been preferable to have two equivalent questions about the governments' responsibility to secure the living standard of families with children/the elderly, but we take the answers to the available question about securing sufficient services for working parents to be a satisfactory proxy for a more general child- and family-friendly orientation.

Our analyses are mainly descriptive and concentrated on variation between country units in terms of spending profiles and (mean) voter preferences. With only 13 country cases, we are not able to do a more sophisticated statistical analysis of the relationship between variables measured at the macro-level, and we therefore rely on descriptive tables and bivariate plots of the respective country scores. In the third part of the empirical analysis, we run a set of country-specific linear regression models on the (microlevel) opinion data in order to reveal a potential age gradient in attitudes toward supporting the old and the young. We present results in terms of standardized regression coefficients in order to make it easier to assess the strength of the association.

Throughout we have used the so-called post-stratification weights provided with the ESS data. These weights are intended to correct for deviations in sampling design from a simple random sampling design of the adult population in the respective countries as well as for systematic sampling errors and nonresponse with respect to the distribution over a set of observed background variables.

\section{Converging or diverging age-related spending profiles?}

Table 3.2 shows figures on spending on income transfers and services directed toward the elderly and toward families with children in each of the 13 countries at the two time points: 2000 and 2015. The level of spending is expressed in the percent of GDP. For each of the two spending categories, we have also added a column showing the change in spending levels between 2000 and 2015 adjusted for changes in the respective population shares (the share of elderly 65 and above and the share of children below the age of 15).

Starting with the elderly, we see that there are significant differences in the level of spending at both time points, and the pattern of variation is roughly in line 
Table 3.2 Public expenditure on income transfers and services to the elderly and to families with children in percent of GDP and change in spending levels adjusted for changes in population shares. 2000 and 2015

\begin{tabular}{|c|c|c|c|c|c|c|}
\hline & \multicolumn{3}{|c|}{ Spending on the elderly } & \multicolumn{3}{|c|}{ Spending on families with children } \\
\hline & 2000 & 2015 & Change & 2000 & 2015 & Change \\
\hline & \multicolumn{6}{|c|}{ Social democratic/Nordic } \\
\hline Sweden & 8.6 & 9.1 & -0.6 & 2.8 & 3.5 & 0.9 \\
\hline Norway & 6.4 & 8.5 & 1.6 & 3.0 & 3.3 & 0.7 \\
\hline Finland & 7.3 & 12.2 & 1.7 & 2.9 & 3.1 & 0.5 \\
\hline \multirow[t]{2}{*}{ Group mean } & 7.4 & 9.9 & 0.9 & 2.9 & 3.3 & 0.7 \\
\hline & \multicolumn{6}{|c|}{ Liberal } \\
\hline United Kingdom & 4.9 & 6.5 & 0.8 & 2.4 & 3.5 & 1.4 \\
\hline Ireland & 2.4 & 3.6 & 0.6 & 2.0 & 2.2 & 0.2 \\
\hline The Netherlands & 4.9 & 6.1 & -0.3 & 1.5 & 1.5 & 0.2 \\
\hline \multirow[t]{2}{*}{ Group mean } & 4.1 & 5.4 & 0.4 & 2.0 & 2.4 & 0.6 \\
\hline & \multicolumn{6}{|c|}{ Conservative/Continental } \\
\hline Germany & 8.4 & 8.3 & -2.0 & 2.0 & 2.2 & 0.6 \\
\hline France & 10.2 & 12.7 & 0.6 & 3.0 & 2.9 & 0.0 \\
\hline Austria & 10.1 & 12.2 & -0.1 & 2.9 & 2.6 & 0.2 \\
\hline Belgium & 6.8 & 9.1 & 0.8 & 2.5 & 2.8 & 0.4 \\
\hline \multirow[t]{2}{*}{ Group mean } & 8.9 & 10.6 & -0.2 & 2.6 & 2.6 & 0.3 \\
\hline & \multicolumn{6}{|c|}{ Southern European } \\
\hline Italy & 11.2 & 13.6 & 0.1 & 1.2 & 2.0 & 0.9 \\
\hline Spain & 6.6 & 9.3 & 1.7 & 0.9 & 1.2 & 0.3 \\
\hline Portugal & 6.6 & 11.6 & 2.5 & 1.0 & 1.2 & 0.4 \\
\hline Group mean & 8.1 & 11.5 & 1.4 & 1.0 & 1.5 & 0.5 \\
\hline
\end{tabular}

Source: OECD SOCX database

with the one observed by Lynch. We find the relatively highest expenditure levels in the Conservative/Continental and Southern European countries followed by the Nordic countries, with the Liberal countries trailing far behind.

It must be noted, however, that the very low level of elderly expenditure in the three "liberal" countries should be seen in light of the fact that these three countries have public old-age pension systems (sometimes referred to as "Beveridgean" systems) that are geared toward minimum protection only, while the responsibility for income-related pension provision and income smoothing over the life cycle is left to occupational pension systems and private retirement saving. In the Netherlands, for instance, all wage earners are covered by quasi mandatory occupational pension schemes that entail large indirect labor costs and transfer economic resources from the economic active age to the retirement phase. It is not entirely obvious therefore that these three countries at the end of the day devote less resources to income provision in retirement, even if they do so to a smaller extent over public budgets.

In all countries, public expenditure on the elderly has increased relative to GDP from 2000 to 2015, with only Germany as an exception. However, when we adjust for the increasing population share taken up by the elderly, we find that four countries have reduced their level spending on the elderly: Germany, 
Sweden, the Netherlands, and Austria. For Germany and Sweden, this is obviously a reflection of the fact that these countries have implemented rather tough retrenchment reforms within their pension systems. The largest increases in per capita spending on the elderly between 2000 and 2015 are found in Portugal, Spain, Finland, and Norway, and in all these four countries a process of continued maturation of fairly young pension systems seems to be a plausible main explanation.

Turning to the pattern of spending on families, we see that the mean level of spending at both time points was highest in the Social Democratic group followed by the Conservative group, while it is lowest in the group of Southern European countries. This pattern is roughly in line with Lynch's theoretical arguments and empirical findings. The only serious deviation is that expenditure on family policies is particularly low in the Netherlands and has remained so also in 2015. The observation of low spending on families with children in Italy, Spain, and Portugal also resonates with the vast research literature that has pointed to underdevelopment of family benefits and services as a key feature of the Southern European welfare states (Rhodes, 1996; Ferrera, 2000, p.169).

However, the last column shows that the per capita spending on (families with) children has increased in all countries except for the Netherlands. The increase is highest in the United Kingdom, Sweden, Italy, Norway, and Germany. In absolute terms, the increase is highest in the Social Democratic group, with 0.7 percentage points, but it is also sizable in the Liberal group with 0.6 and in the Southern European group with 0.5 . The increase is modest in the group of Conservative/ Continental taken together, but within this group, Germany stands out with a sizable increase of 0.6 percentage points. In relative terms, the increase is strongest in the Southern European and the Liberal groups, and it is therefore fair to say that we do observe a tendency toward upward convergence in the level of spending on families with children.

In Table 3.3, we have calculated the ratio between per capita spending on the elderly (age 65+) and on children (expenditure on family policy per child under the age of 15).

In 2015, we find the lowest pro-elderly bias in expenditure in the United Kingdom with a ratio of 1.8 between per capita expenditure on the elderly and children under 15 , followed by Germany and Sweden with a ratio of 2.3. At the other extreme we find Portugal, Spain, and Italy with per capita spending ratios in favor of the elderly at $6.6,6.0$, and 4.3 , respectively.

As expected, the spending ratio in favor of the elderly is most pronounced in the Southern European welfare states, followed by the Conservative/Continental group, while it is lowest in the Social Democratic and the Liberal groups. This overall pattern, that obtains at both time points, is well in line with the findings by Lynch.

However, in a majority of the countries, the spending "bias" toward the elderly has declined somewhat between 2000 and 2015. The decline is most pronounced in Italy, although from a very high level, but also Germany and Sweden have seen very sizable declines of 1.6 and 1.0 , respectively. 
Table 3.3 Ratio between per capita spending on the elderly (65+) and families with children (children $<15$ )

\begin{tabular}{lccc}
\hline & 2000 & 2015 & Change \\
\hline & & Social democratic/Nordic & \\
Sweden & 3.3 & 2.3 & -1.0 \\
Norway & 2.8 & 2.9 & 0.1 \\
Finland & 3.0 & 3.2 & 0.2 \\
Group mean & 3.0 & 2.8 & -0.2 \\
& & Liberal & \\
United Kingdom & 2.4 & 1.8 & -0.6 \\
Ireland & 2.5 & 2.8 & -0.3 \\
The Netherlands & 4.6 & 3.9 & -0.7 \\
Group mean & 3.2 & 2.8 & -0.5 \\
& & Conservative/Continental & \\
Germany & 3.9 & 2.3 & -1.6 \\
France & 4.0 & 4.2 & 0.2 \\
Austria & 3.8 & 3.5 & -0.3 \\
Belgium & 2.9 & 3.0 & 0.1 \\
Group mean & 3.7 & 3.3 & -0.4 \\
& & Southern European & \\
Italy & 7.5 & 4.3 & -3.2 \\
Spain & 6.2 & 6.0 & -0.2 \\
Portugal & 6.7 & 6.6 & -0.1 \\
Group mean & 6.8 & 5.6 & -1.2 \\
\hline
\end{tabular}

Source: OECD SOCX database

In all country groups, the general tendency points toward decreasing elderly bias in per capita expenditure. The decline is particularly large in the Southern European group with a decline of 1.2 points on average. It should be noted that this decline in the group mean is almost entirely driven by Italy, where the proelderly bias in expenditure has decreased from a ratio of 7.5 to a ratio of 4.3. In Portugal and Spain, per capita expenditure on families with children has increased as well, but here this has been balanced with increasing expenditure in favor of the elderly.

We can therefore conclude with quite significant tendencies toward downward convergence in pro-elderly spending ratios between 2000 and 2015. The overall ranking of the four country groups is intact, but the differences have become less pronounced.

\section{Cross-country variation in voter preferences}

We now turn to investigate voter preferences on government support for the elderly and for families with children and whether there is a correspondence between cross-national variation in the age orientation of welfare state spending and voters' priorities. We look at three aspects: (1) the degree of support for 
government responsibility for the elderly, (2) the degree of support for family policies (i.e. services to working parents), and (3) the difference in the degree of support for the two groups in favor of the elderly.

Voters in all countries tend to be relatively supportive of the idea that the government should take responsibility for the elderly as well as for families with children. On a scale of 0 to 10 , the mean country scores with respect to government support for the elderly vary between 8.6 (Portugal) to 7.4 (the Netherlands). The corresponding scores with respect to family policy tend to be slightly lower in most countries and also more dispersed, varying between 8.6 in Portugal and 6.1 in the Netherlands. It should be emphasized, however, that also here the mean scores are everywhere well above 5, the natural midpoint of the scale. The questionnaire also contains a similar question about government responsibility toward the unemployed, and here the mean score for the entire pooled sample is clearly lower at 6.8 , compared to mean scores of 7.7 for supporting families and 8.0 for supporting the elderly.

The cross-national pattern of support for the elderly is in line with expectations with the highest support in the (notoriously elderly friendly) Southern European countries, with a mean score of 8.5 and lowest in the Liberal group with a mean score of 7.7 .

The pattern of support for government responsibility in the area of family policy is however somewhat surprising. Here we find significantly stronger crossgroup variation, and it turns out that voters in the Southern European countries have the highest score here as well, with a mean score of 8.2 in favor of supporting families. This is followed by the Social Democratic/Nordic group and the Conservative/Continental group with mean scores of 8.0 and 7.8, while the Liberal group is trailing significantly behind with a mean score of 6.7.

The third column shows that voters in most countries tend to be somewhat more supportive of policies to cater to the elderly compared to policies directed toward families. The largest pro-elderly bias in voter preferences is found in the Netherlands, with a difference of 1.3 scale points, followed by the United Kingdom and Ireland with 0.8 scale points. Germany deviates from the remaining 12 countries with a negative score of 0.9 on this variable. In Germany, family policies appear to be more popular than policies catering to the elderly.

The strongest pro-elderly bias in voter preferences is found in the Liberal group with a mean difference of 1.0 scale points. The mean scores in the three remaining country groups are all fairly close to zero, indicating a balanced voter support for policies directed toward the old and families. The group means hide significant within group differences, however. In the Conservative/Continental group, there is a stark contrast between a relatively strong pro-elderly bias in France and a strong pro-family bias in Germany. Among the Southern European countries voters show a significant pro-elderly bias in Spain, while voters in Portugal show a balanced high degree of support for government policies in favor of the old and the young.

In order to bring out the relationship between the actual spending priority of elderly versus families (based on the ratio for 2015 in Table 3.4) and how the voters 
Table 3.4 Attitudes toward government's responsibility toward elderly and families with children. Mean scores

\begin{tabular}{|c|c|c|c|}
\hline & $\begin{array}{l}\text { Support for the } \\
\text { elderly }\end{array}$ & $\begin{array}{l}\text { Support for families with } \\
\text { children }\end{array}$ & $\begin{array}{l}\text { Difference in favor of the } \\
\text { elderly }\end{array}$ \\
\hline \multicolumn{4}{|c|}{ Social democratic/Nordic } \\
\hline Sweden & 8.0 & 7.8 & 0.2 \\
\hline Norway & 8.2 & 8.2 & 0.0 \\
\hline Finland & 8.1 & 8.0 & 0.1 \\
\hline \multicolumn{4}{|c|}{ Liberal } \\
\hline United Kingdom & 7.8 & 7.0 & 0.8 \\
\hline Ireland & 7.9 & 7.1 & 0.8 \\
\hline The Netherlands & 7.4 & 6.1 & 1.3 \\
\hline \multicolumn{4}{|c|}{ Conservative/Continental } \\
\hline Germany & 7.6 & 8.4 & -0.9 \\
\hline France & 7.9 & 7.4 & 0.5 \\
\hline Austria & 8.0 & 7.9 & 0.1 \\
\hline Belgium & 7.8 & 7.6 & 0.3 \\
\hline \multicolumn{4}{|c|}{ Southern European } \\
\hline Italy & 8.5 & 8.1 & 0.3 \\
\hline Spain & 8.5 & 8.0 & 0.5 \\
\hline Portugal & 8.6 & 8.6 & 0.0 \\
\hline Group mean & 8.5 & 8.2 & 0.3 \\
\hline
\end{tabular}

Note: Standard deviations of the estimated country means vary between 0.03 and 0.06 .

Source: ESS Round 8. 2016

prioritize the two groups (based on the difference in favor of elderly in Table 3.4), Figure 3.1 shows a scatterplot of the respective country scores on these two dimensions.

The distribution of country cases on these two dimensions does not bear witness to a strong systematic correlation between actual spending pattern and voters' priorities. Among the four countries with a lowest spending bias in favor of the elderly (the United Kingdom, Germany, Sweden, and Ireland), voter preferences differ quite dramatically. Voters in the United Kingdom and Ireland are among the most pro-elderly biased in our country sample. Germany, on the other hand, is the only country where voter preferences are distinctly pro-family oriented. The country with the strongest elderly-biased preferences in the electorate, the Netherlands, features a spending pattern close to the sample mean. The two countries with the strongest pro-elderly spending profile, Portugal and Spain, both have voters who are either perfectly balanced in their strong support for policies favoring both sides of the life cycle (Portugal) or voters with a sizable pro-elderly bias (Spain). 


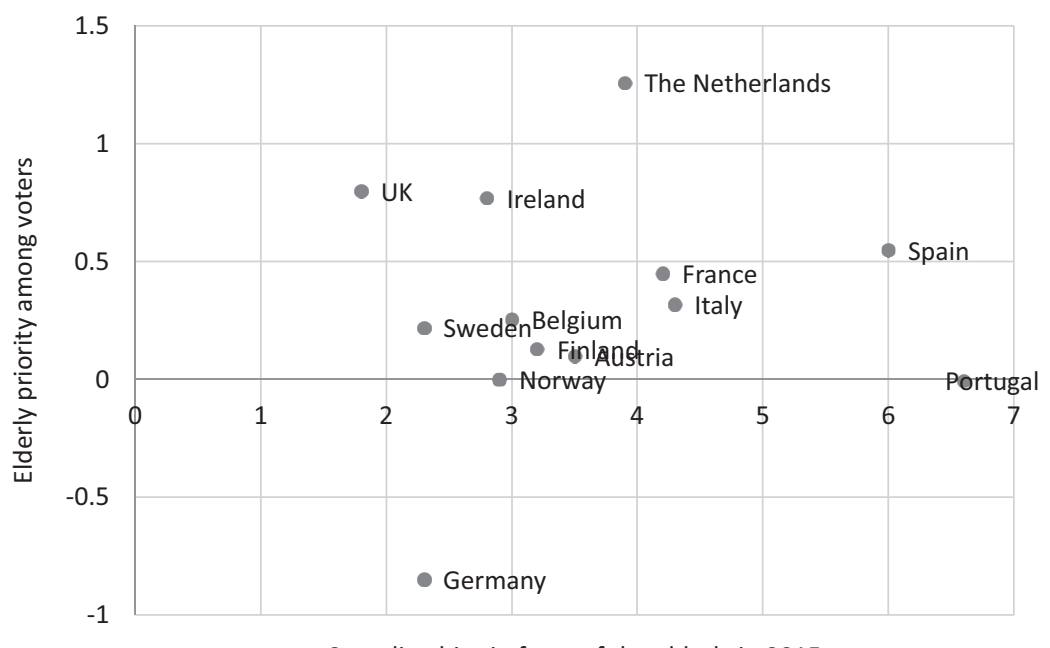

Spending bias in favor of the elderly in 2015

Figure 3.1 Elderly priority among voters (2016) and spending bias in favor of the elderly in 2015.

\section{Disagreement across age groups?}

The question remains whether attitudes toward welfare provision in favor of the elderly and families show a stronger association with age in some countries compared to others. Based on the theoretical framework adopted by Lynch, we expect a stronger self-interest-related age division in countries belonging to the Conservative/Continental and Southern European groups compared with countries belonging to the presumably more citizen-oriented Social Democratic and Liberal groups. To test the hypothesis, we have run a series of country-specific regression analyses with age as the independent variable and with the three voter preference variables as dependent variables. The results are presented in Table 3.5.

We find a significant negative age gradient with respect to support for families with children in 6 out of the 13 countries, and the tendency for a negative association with age is strongest and most consistent among countries belonging to the Liberal and Social Democratic groups, with the strongest negative association found in the United Kingdom. Even here the relationship is not particularly strong. One standard deviation increase in age is associated with 0.19 standard deviation decrease in support for families with children. Among the six countries belonging to these two welfare state groups, only Finland deviates by showing attitudes toward supporting families that appear unrelated to age. Among countries belonging to the Conservative/Continental and Southern European groups, the picture is mixed. In Germany, we find a significant negative age gradient, 
Table 3.5 Country-specific OLS regression with age as independent variable. Dependent variables: support for families with children, support for the elderly, and difference in favor of the elderly. Standardized regression coefficients

\begin{tabular}{lccl}
\hline & $\begin{array}{l}\text { Support for } \\
\text { families }\end{array}$ & $\begin{array}{l}\text { Support for the } \\
\text { elderly }\end{array}$ & $\begin{array}{l}\text { Difference in favor } \\
\text { of the elderly }\end{array}$ \\
\hline Sweden & $-0.1 * * *$ & Social democratic/Nordic & \\
Norway & $-0.09^{* * *}$ & $0.06^{*}$ & $0.14^{* * *}$ \\
Finland & 0.02 & -0.03 & $0.06^{*}$ \\
United Kingdom & $-0,19^{* * *}$ & -0.01 & -0.02 \\
Ireland & $-0.08^{* * *}$ & 0.01 & $0.19^{* * *}$ \\
The Netherlands & $-0.05^{*}$ & $0.15^{* * *}$ & $0.19^{* * *}$ \\
Germany & 0.02 & $0.06^{*}$ \\
France & $-0.08^{* * *}$ & Conservative/Continental & -0.03 \\
Austria & 0.00 & $-0.11^{* * *}$ & 0.01 \\
Belgium & 0,01 & 0.01 & $0.11^{* * *}$ \\
Italy & $0.06^{*}$ & $0.12^{* * *}$ & 0.03 \\
Spain & $0.10^{* * *}$ & $0.05^{* *}$ \\
Portugal & 0.04 & Southern European & $0.05^{*}$ \\
\hline
\end{tabular}

Source: ESS Round 8. 2016. * indicates that a coefficient is significant at the $5 \%$ level, ** at the $1 \%$ level, and $* * *$ at the $0.1 \%$ level.

while in Belgium and Portugal the age gradient is in fact reversed so that support for family-friendly policies is increasing with age.

The age gradients for support for elderly policies are generally somewhat weaker and more inconsistent. Support for the elderly is positively related to age in eight countries: Ireland, Austria, Italy, Belgium, Portugal, Sweden, and Spain. In one country, Germany, support for the elderly is in fact clearly negatively related to age.

The between-group pattern is rather mixed. The most consistent positive age gradient related to policies for the elderly is found among the three countries in the Southern European group. Among the three remaining country groups, the gradients are either consistently weak (the Social Democratic/Nordic group) or inconsistent (the Liberal and the Conservative/Continental group).

The third column shows that the tendency to favor support for the elderly is positively related to age in eight countries. The age gradient is by far the strongest in Ireland and the United Kingdom, where a standard deviation increase in age is associated with an increase of 0.19 standard deviation in the dependent variable. Also in Sweden and Austria we find a substantial and clearly significant age gradient, while the age gradient is weaker in Norway, the Netherlands, Italy, and Spain. In Germany, Finland, and Portugal, the age gradient is in fact negative, but without reaching statistical significance. 
Age conflicts over welfare priorities appear to be strongest in the Liberal countries followed by the Social Democratic countries, that is in countries that were classified by Lynch as having a legacy of citizen-based policies.

Finally, it should be pointed out that in some countries we find a significant age gradient in the same direction in the preferences with respect to support for both demographic groups. This is the case for Belgium and Portugal in particular. In these two countries, elderly respondents show consistently more pro-welfare attitudes compared to younger respondents, and the positive age gradients with respect to the two program areas tend to cancel out so that we find no gradient for the difference variable. Germany is an example of the complete opposite pattern. Here the young are more pro-welfare than the elderly irrespective of the program area. Ireland shows a third, distinctively different pattern. In this country, a negative age gradient with respect to support for family policy is combined with a positive gradient with respect to support for the old, and these two tendencies combine to produce a strong age conflict (only matched by the United Kingdom) over welfare priorities between supporting families and supporting the old as measured by the difference variable.

Our initial hypothesis that age conflicts over welfare priorities should be strongest in the countries with a strong pro-elderly spending pattern is not borne out. This is demonstrated more clearly in Figure 3.2. If it is at all meaningful to talk about a linear association here, it is in the opposite direction due to the contrast between Portugal and Spain (combing a high spending bias toward the elderly with no age conflict in voter preferences) and the United Kingdom, Ireland, and

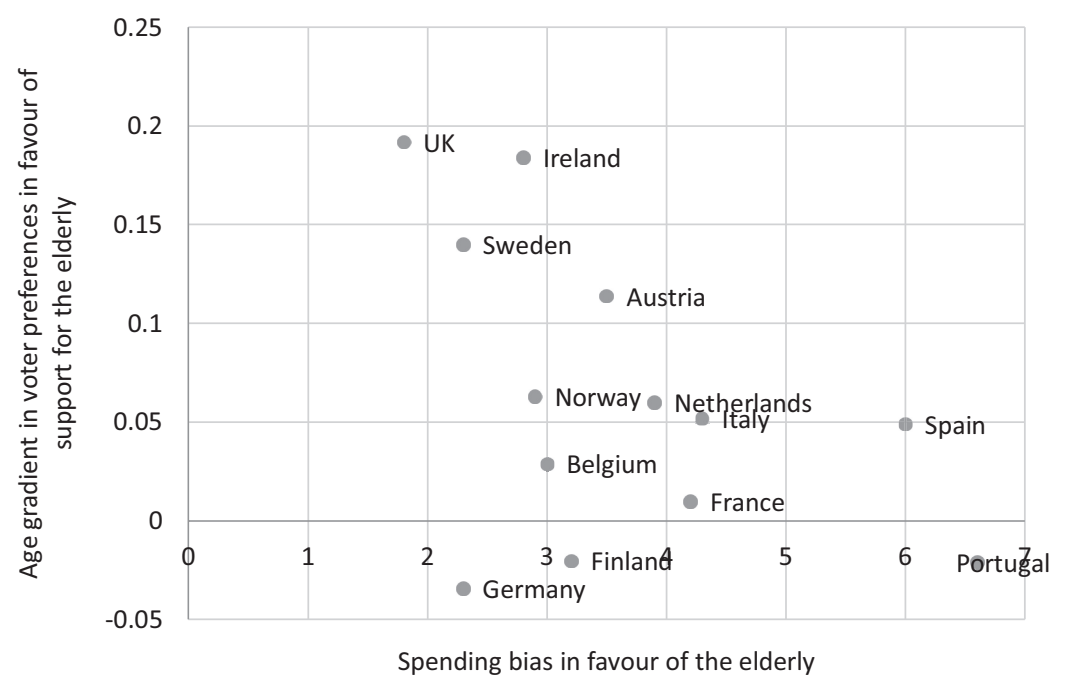

Figure 3.2 Age gradient in voter preferences favoring support for the elderly (standardized regression coefficients) and spending bias in favor of the elderly in 2015. 
Sweden (combining a modest pro-elderly spending bias with a relatively strong age conflict in voter preferences).

\section{Summary}

This chapter is motivated by the anticipation of increased tensions between generations about the distribution of benefits and burdens within the welfare state. Our investigation of the development of expenditure revealed that the spending "bias" toward the elderly has declined somewhat in all countries. This clearly goes against the idea that a greying electorate will force the welfare state to cater exclusively for the needs of the old. The decline in elderly bias is most pronounced in Italy, which traditionally is one of the most elderly-oriented countries in the sample. At the same time, the spending ratio in favor of the elderly has declined less in the countries belonging to the Liberal and Social democratic groups where the pro-elderly bias was less pronounced already in the year 2000. Both findings indicate a tendency toward convergence in the ratio per capita expenditure on the elderly and children. Preston's diagnosis of a greying electorate pressing forward pro-elderly policies at the expense of families with children is rejected by our analysis. Even the Southern European countries that have been claimed to be caught in a pathological pro-elderly path dependence (see Rhodes, 1996; Ferrera, 2000; Lynch, 2006) show signs of convergence toward a more balanced mixture of expenditure on the young and the old.

We went on to examine whether the preferences of the voters mirrored the spending profiles of their country, or if cross-national similarities in voters' preferences could be a force pointing toward convergence. One robust finding is that European voters are rather supportive of the idea that the state should take responsibility for the wellbeing of both the elderly and the families, while the support for the state taking responsibility for the unemployed is significantly lower. The finding is in line with Jensen's (2012) conclusion that the median voter is more inclined to favor life cycle-oriented social programs than programs with a social class gradient. At the same time, European voters are found to be somewhat more supportive toward public responsibility for the elderly than toward responsibility for families. Only in Germany, we find the complete opposite pattern with voters being more enthusiastic toward supporting families than they are toward supporting the elderly.

The comparison of voters' preferences across countries does not align neatly with expectations based on welfare state typologies and the countries' actual spending pattern. In some respects, voter attitudes are at odds with spending patterns in their country, and hence voters appear to show a demand for change and mostly in the direction of convergence. The most obvious example is the finding that voters in the Southern European countries appear to be at least as supportive of family policies as voters in the other country groups. Conversely, but in a similar vein we find the strongest pro-elderly bias in voter preferences in the Netherlands, United Kingdom, and Ireland, all countries with a comparatively low spending on the elderly. Germany is the only country where voters are more 
supportive toward government responsibility for families than toward the elderly. At the same time, Germany is among the countries with the largest decline in the elderly bias of actual welfare spending. It is tempting to speculate that a stronger emphasis on support for working families in German welfare policy over the last decade has been facilitated by a particularly child- and family-friendly public opinion.

We do find a rather modest age gradient in attitudes toward public spending patterns. The age gradient is mainly visible with respect to support for spending on families, and it affects also the priority given to spending on the elderly over spending on families. Our initial hypothesis that age conflicts should be strongest in the countries with a strong elderly-biased spending pattern is not supported. On the contrary, age conflicts over spending patterns tend to be the strongest in the Liberal and (to a smaller extent) Social democratic countries where the spending pattern is relatively balanced. In some countries we see a parallel age gradient in support for spending on both the elderly and the families with children. This is the case in Belgium and Portugal, where older respondents tend to be consistently more supportive of welfare policies favoring either the elderly or families compared to younger respondents. Also in Germany, we find parallel age gradients, but here they are consistently negative. Younger respondents are more pro-welfare with respect to both program areas than older respondents. In these three countries, there are tensions between generations in welfare attitudes, but these tensions appear not to be driven by a simple conflict of interest between the young and the old.

\section{Discussion}

Despite huge differences in the design and the size of welfare states, all developed democracies have acknowledged a certain level of responsibility for the economic wellbeing of the elderly in society. The establishment of national pension systems providing financial support to the elderly has been a cornerstone of all developed welfare states. The younger generations have been relieved of the responsibility of providing for elderly family members, and the elderly themselves have acquired increased autonomy and economic independence from their children. There is more cross-national variation in the tendency for the state to take responsibility for providing services to elderly in need of care. Here the Nordic countries have been frontrunners while both countries belonging to the Liberal, Conservative, and, in particular, the Southern European welfare state-type have tended to lag behind. For the Southern European countries, an obvious part of the explanation is the very high expenditure on pensions, which leaves little room for public expenditure on services to the elderly. But also more traditional gender roles and the associated underdevelopment of transfers and services to working families contribute to lock in the Southern European countries in an elderly friendly and transfer-dominated profile of welfare spending. Where public responsibility for elderly care has been taken furthest - like in the Nordic countries in particular it has helped facilitate and at the same time been dependent upon a substantial 
growth in women's participation in the labor market. It is no coincidence therefore that also family policies have traditionally been furthest developed in the Nordic countries, again with the Southern European countries as persistent laggards.

Given the traditional familialism in the Southern European welfare states and the comparatively low spending on families in Italy, Spain, and Portugal, the support voters in these countries express toward state responsibility for childcare services for working parents is somewhat surprising. That the support is equally strong among young and old indicates that voters do not consider an increased public responsibility for families as a challenge to the benefits directed toward old age. An intergenerational perspective might help explain this. Low availability of public day care combined with sparse benefits to families with small children discourage family reproduction as well as female participation in the labor market (Ferrera, 2000). Voters might realize that the intergenerational contract erodes if young couples fail to reproduce themselves. Additionally, a system with generous public pensions toward elderly is dependent upon high participation in the labor market among citizens in the working age part of the population. To enable female participation in the labor market through public care, strengthen the financial basis for public pensions.

Several studies have shown that public responsibility for the elderly receives particular strong support among voters (Coughlin, 1980; Bay, 1998; Svallfors et al, 2012). The pattern seems to be more or less stable over time and across countries with different levels and designs of their welfare state, indicating that the preferences are at least partially exogenous. One obvious explanation is selfinterest, shared by large segments of the electorate as pointed out by Preston. Additionally, care and respect for one's elderly is deeply rooted in the culture of most societies, in Christianity it is embodied in the fourth of the ten amendments in the Bible. Europeans' (in our case) shared and internalized duty toward the elderly is a powerful constant premise in the politics of social policies. At the same time, the "communication" between voters and policymakers takes place through existing policies and institutional structures. Voters' preferences are endogenous in the sense that they relate to the established path of social policy development, as pointed out in the theory of path dependency. Paul Pierson $(1996 ; 1998 ; 2001)$ argued in his important contributions on the politics of retrenchment that the strong popular support for existing pension systems (and other welfare benefits) represents an "immovable object" confronted with "the irresistible force" in demographic and economic change. Our findings leave us with a somewhat more optimistic picture. Several countries have decreased their per capita spending on the elderly and subsequently reduced their elderly bias in per capita expenditure. The political elite has a room to maneuver through elite cooperation (Schmidt, 2008) and through the framing of the communication with their voters.

The aging of the population combined with lower economic growth will for most European societies reinforce the need to weigh these interests against each other. Many see age as a new potential political cleavage, either crowding out traditional socioeconomic and cultural cleavages or filling the gap caused by a weakening of traditional lines of conflicts within the electorate. Objective conflicts of 
interests are however not enough to constitute a political cleavage; the interests must be self-perceived by a group and mobilized by a political party or another political actor (Bartolini \& Mair, 1990). The substantial support toward government responsibility for the welfare of the elderly as well as families with children and the lack of a strong and consistent age gradient in voters' preferences documented in our study lead us to the conclusion that age is an unlikely political dividing line in European societies. The reasons for a lack of self-perceived group conflicts between the elderly and the younger segments of society are already touched upon; large parts of the population have vested interests in benefits toward elderly, conflicts of interests are modified by intergenerational solidarity within the family (cf. the study of Goerres \& Tepe, 2010 cited in the introduction), and a sustainable policy toward the elderly is dependent upon policy measures that promote fertility and labor market participation among parents with younger children.

Seen from the perspective of social cohesion, the lack of distributional conflicts between the elderly and the nonelderly is good news. At the same time, it underlines the challenges Pierson, among others, has identified related to the policymakers' ability to make priorities. It might be easier for politicians competing for power to position themselves in a situation where the electorate is divided based on clearly defined conflicts of interests, than in a situation where they have to deal with challenges related to demographic and economic developments that tend to be ignored by a welfare demanding median voter.

\section{Note}

1 In this chapter, we simply define generations as bands of birth cohorts that at a particular historical moment occupy a specific age group.

\section{References}

Bartolini, S. \& Mair, P. (1990). Identity, Competition and Electoral Availability. Cambridge: Cambridge University Press.

Bay, A-H. (1998). Mass Opinion and Public Policy Towards Elderly. NOVA Report 24/98. PhD-Dissertation.

Buchanan, J.M. \& Tullock, G. (1969). The Calculus of Consent. Logical Foundations of Constitutional Democracy. Ann Arbor, MI: University of Michigan Press.

Busemeyer, M.R., Goerres, A., \& Weschle, S. (2009). Attitudes towards redistributive spending in an era of demographic aging: The rival pressures from age and income in 14 OECD countries. Journal of European Social Policy, 19: 195-212. https://doi.org $/ 10.1177 / 095828709104736$

Coughlin, R. (1980). Ideology, Public Opinion and Welfare Policy. Berkeley, CA: University of California Press.

Esping-Andersen, G. (1990). The Three Worlds of Welfare Capitalism. Cambridge: Polity Press.

Feldman, S. \& Zaller, J. R. (1992). The political culture of ambivalence: Ideological responses to the welfare state, American Journal of Political Science 36: 268-307. https://doi.org/10.2307/2111433 
Fernández, J.J. (2012). Population ageing, the elderly, and he generosity of standard and minimum pensions, in Vanhuysse, P. and Goerres, A. (eds.) Ageing Populations in Post-industrial Democracies. Comparative Studies of Policies and Politics. New York: Routledge.

Ferrera, M. (1996). The 'southern model' of welfare in social Europe. Journal of European Social Policy 6(1): 17-37. https://doi.org/10.1177/09582879600600102

Ferrera, M. (2000). Reconstructing the welfare state in Southern Europe, in Kuhnle, S. (ed.) The Survival of the European Welfare State. New York: Routledge.

Goerres, A. \& Tepe, M.S. (2010). Age-based self-Interest, intergenerational solidarity and the welfare state: A comparative analysis of older people's attitudes towards public child-care in 12 OECD-countries. European Journal of Political Research 49(6): 818851. https://doi.org/10.1111/j.1475-6765.2010.01920.x

Heclo, H. (1988). Generational politics, in Palmer, J.L., Smeeding, T. and Torrey, B.B. (eds.) The vulnerable. Washington D.C: The Urban Institute Press.

Jensen, C. (2012). Labour market - versus life course related social policies: Understanding cross-programme differences. Journal of European Public Policy, 19 (2): 275-291. DOI:1080/13501763.2011.599991

Leibfried, S. (1992). Towards a European welfare state? On integrating poverty regimes into the European community, in Z. Ferge \& J. E. Kolberg (eds) Social Policy in a Changing Europe. Routledge. https://doi.org/10.1080/13501763.2011.599991

Lynch, J. (2006). Age in the Welfare State. The Origins of Social Spending on Pensioners, Workers, and Children. Cambridge: Cambridge University Press.

de Mello, L., Schotte, S., Tiongson, E.R. \& Winkler, H. (2016). Greying the Budget: Ageing and Preferences over Public Policies. IZA Discussion Paper Series No. 9681. Bonn: IZA.

OECD (2019). The OECD SOCX Manual. 2019 Edition. Paris: OECD. http://www.oecd .org/social/soc/SOCX_Manuel_2019.pdf

Palier, B. (ed.) (2010). A Long Goodbye to Bismarck? The Politics of Welfare Reform in Continental Europe. Amsterdam: Amsterdam University Press.

Persson, T. \& Tabellini, G. (2000). Political Economics: Explaining Economic Policy. Cambridge: MIT.

Pierson, P. (1996). The new politics of the welfare state. World Politics, 48(2): 143-79. https://doi.org/10.1353/wp.1996.0004

Pierson, P. (1998). Irresistible forces, immovable objects: post-industrial welfare states confront permanent austerity. Journal of European Public Policy, 5(4): 539-60. https:/ /doi.org/10.1080/13501769880000011

Pierson, P. (2001). Coping with permanent Austerity: Welfare state restructuring in affluent democracies, in Pierson, P. (ed). The New Politics of the Welfare State. Oxford: Oxford University Press. DOI:10.1093/0198297564.003.0014

Preston, S.H. (1984). Children and elderly: divergent paths for America's Dependents. Demography, 21(4): 425-57. Doi: 10.2307/2060909

Rhodes, M. (1996). Southern European welfare states: Identity, problems and prospects for reform. South European Society and Politics. Vol 1, issue 3: 1-22. DOI: $10.1080 / 13608749608539480$

Roosma, F., van Oorschot, W., \& Gelissen, J. (2014). The preferred role and perceived performance of the welfare state: European welfare attitudes from a multidimensional perspective. Social Science Research, 44C: 200-219. https://doi.org/10.1016./j.ssresear ch.2013.12.005

Schmidt, V.A. (2003). The boundaries of "bounded generalizations": Discourse as the missing factor in actor-centered institutionalism, in M. Renate \& S. Wolfgang (eds.) 
Die Reformierbarkeit der Demokratie. Innovationen und Blockaden (pp. 318-350). Frankfurt: Campus.

Schmidt, V.A. (2008). Discursive institutionalism: The explanatory power of ideas and discourse. Annual Review of Political Science, 11: 303-326. https://doi.org/10.1146/a nnurev.polsci.11.060606.135342

Sears, D.O. \& Funk, C. L. (1990). Self-interest in Americans' political opinions, in Mansbridge, J.J. (ed.) Beyond Self-interest. Chicago, IL: The University of Chicago Press.

Sniderman, P. M., Brody, R. A. \& Tetlock, P. E. (1991). Introduction: Major themes, in Sniderman, P. M, Brody, R. A. \& Tetlock, P. E (eds.). Reasoning and Choice. Explorations in Political Psychology. Cambridge: Cambridge University Press.

Van Oorschot, W. (2006). Making the difference in social Europe: Deservingness perceptions among citizens of European welfare states. Journal of European Social Policy, 16: 23-41. https://doi.org/10.1177/0958928706059829

Svallfors, S. Kulin, J. \& Schnabel, A. (2012). Age, class, and attitudes toward government responsibilities, in Svallfors, S. (ed). Contested Welfare States. Welfare Attitudes in Europe and Beyond. Stanford, CA: Stanford University Press.

Torp, C. (ed.) (2015). Pensions, Retirement and Generational Justice. New York: PalgraveMacmillan.

Vanhuysse, P. \& Goerres, A. (eds.) (2012). Ageing Populations in Post-Industrial Democracies. Comparative studies of policies and politics. New York: Routledge. 